\title{
Socioeconomic impact of irritable bowel syndrome in Canada
}

\author{
Michel Boivin MD FRCPC
}

M Boivin. Socioeconomic impact of irritable bowel syndrome in Canada. Can J Gastroenterol 2001;15(Suppl B):8B-11B. Irritable bowel syndrome (IBS) is the most common functional gastroenterological disorder reported to physicians. In Canada, its prevalence is about $6 \%$. In the United States and the United Kingdom, the prevalence is estimated to be closer to $15 \%$. Patients with IBS tend to make extensive use of health care services, even though a high percentage of them do not seek medical advice. The costs of IBS are a large expenditure of scarce resources. These costs can be divided into several categories: direct, indirect and intangible costs. The direct costs, associated with the diagnosis and treatment, are largely sustained by the health care system. The indirect costs are related to the production losses due to morbidity, and intangible costs are associated with the pain, suffering and alteration in the patient's quality of life. The condition is a diagnosis of exclusion, and treatment, although beneficial, is rarely curative. The general treatment approach stresses the importance of a good physician-patient relationship. Exploring the nature of the expenses associated with IBS and understanding how treatment options may affect these costs are essential to reducing its financial burden.

\section{Incidence socio-économique du syndrome du côlon irritable au Canada}

RÉSUMÉ : Le syndrome du côlon irritable (SCI) est le trouble digestif fonctionnel le plus fréquent que rencontrent les médecins. Sa prévalence se situerait aux alentours de $6 \%$ au Canada et de $15 \%$ aux États-Unis et au Royaume-Uni. Les patients souffrant du SCI ont tendance à recourir souvent aux services de santé, même si un pourcentage élevé d'entre eux ne consultent pas de médecins. Les coûts liés au SCI font une sérieuse ponction dans de maigres ressources. On peut diviser les coûts en trois catégories : directs, indirects et intangibles. Les coûts directs associés au diagnostic et au traitement sont en grande partie assumés par le système de santé. Les coûts indirects sont liés à la perte de productivité due à la morbidité et les coûts intangibles sont associés à la douleur, aux souffrances et à la diminution de la qualité de vie. Le diagnostic repose sur l'exclusion d'autres troubles et le traitement, même s'il apporte un certain soulagement, est rarement curatif. Le traitement général fait appel à une bonne relation médecin-patient. Il est essentiel de comprendre la nature des dépenses liées au SCI et l'incidence des différentes options thérapeutiques sur les coûts si on veut réduire le fardeau financier de ce trouble digestif.

Key Words: Gastroenterological disorder; Irritable bowel syndrome

$\mathrm{T}$ he irritable bowel syndrome (IBS) is a chronic gastrointestinal disorder that is characterized by abdominal pain and disturbed defecation. The mechanisms are unexplained; there are no known structural or biochemical abnormalities. The disease has no biological markers that may be used to determine when and if patients are suffering from the con- dition. Symptomatically, it mimics many other gastroenterological disorders. Diagnosis is achieved primarily by the exclusion of other structural abnormalities and by positive identification of symptoms consistent with the condition. The greatest financial expenditures associated with IBS are those related to health resource utilization, primarily for the 
diagnosis and treatment. Patients tend to make extensive use of health care services and are a large financial burden on society. Other costs, such as production losses associated with the illness, also have a significant financial impact on society. Understanding the nature of the costs that are related to all aspects of this disease complex may help to formulate future cost effective therapeutic strategies.

\section{PREVALENCE AND EPIDEMIOLOGY}

IBS is a common complaint of patients who seek medical care for gastroenterological symptoms. The prevalence of the disease in Canada has been estimated at $6.2 \%$, while in the United States the prevalence can be as high as $15 \%$ of the population $(1,2)$. Although IBS is particularly common in Western societies, studies indicate that it has worldwide significance. In 1980, the prevalence in Britain was found to be $14 \%$. France, New Zealand, Denmark and China reported a similar prevalence (3). Although most patients with the condition do not seek medical attention, IBS is one of the most common diagnoses, comprising approximately $12 \%$ of primary care and $28 \%$ of gastroenterology practices (4).

Age, sex and possibly race appear to be related risk factors. The illness affects a higher percentage of women $(14 \%$ to $24 \%$ ) than men ( $5 \%$ to $19 \%$ ) and appears to affect white people and black people equally. However, a reduced prevalence in hispanics has been observed (5). There also appears to be a reduced prevalence among older subjects. The syndrome is a chronic relapsing condition and it is believed to occur in most adults at some point in their lives. Symptoms usually begin before the age of 35 years in $50 \%$ of patients, and $40 \%$ of patients are between 35 and 50 years of age at the onset of the disease. IBS is recognized and diagnosed in children, and many patients can trace the start of their symptoms back to childhood (6-8).

\section{ECONOMIC IMPACT OF IBS}

The expenses associated with IBS are diverse. The origin of these costs can be broken down into several categories: direct costs due to the disease, the cost of treating the depression and anxiety created by, and associated with, the condition, and finally costs due to concurrent disease. A study by Talley (9) found that approximately one-third of people with functional dyspepsia also suffered from IBS. Due to the nature of the expenditures, it often becomes difficult to separate the true cost of IBS from those that are only related, because all costs may not be disease-specific. Because patients have a wide variety of symptoms, the actual costs can only estimate the total costs related to IBS. For example, a 1999 survey conducted among 1036 Canadians showed that constipation occurred in $9 \%$ of patients with diagnosed IBS. Of the patients surveyed, only $29 \%$ with IBS sought medical attention. Among the patients treated by a physician, $43 \%$ indicated that the recommended treatment was either 'not very effective' or 'not effective at all'. Some patients (41\%) who used nonprescription medications also found that they were either 'not

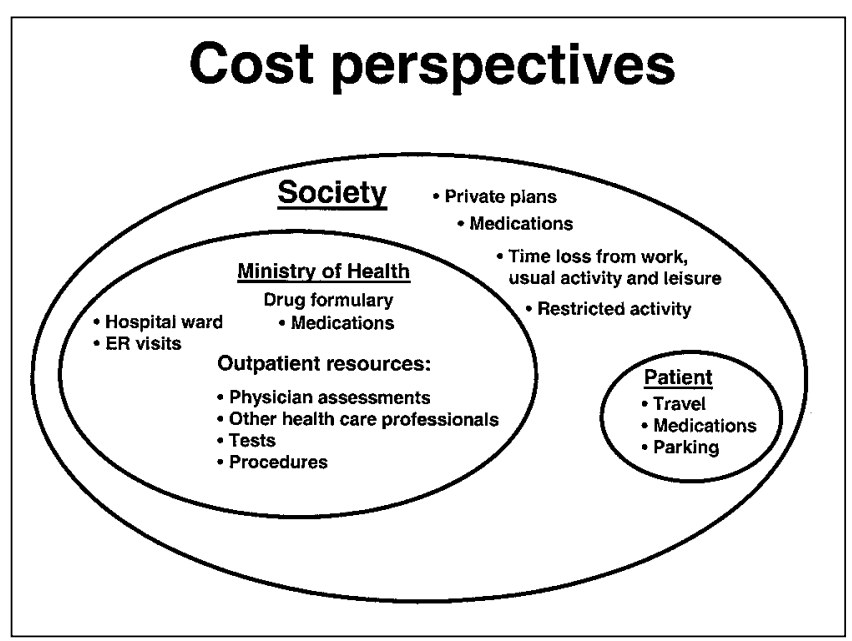

Figure 1) Direct cost perspectives related to irritable bowel syndrome

very effective' or 'not effective at all'. Currently, there is limited information on the burden and cost associated with constipation.

The economic impact of this illness, or the burden of the illness on society, has basically three components: direct costs, indirect costs and intangible costs. The cost perspectives, summarized in Figure 1, take into account the direct financial impact. These direct costs are principally sustained by the health care system and are associated with the diagnosis and treatment of the disease. Examples of direct costs associated with IBS include visits to the physician, consults with a specialist, tests ( $\mathrm{x}$-ray, endoscopy), time lost from work, drugs (prescription and nonprescription) and alternative care (herbals, acupuncture or hypnotherapy). The indirect costs are mostly derived from the production losses that are attributable to morbidity or premature mortality. The intangible costs result from the pain, suffering and the alteration in the quality of life caused by the disease.

Based on studies in the United States, patients with IBS represent a substantial financial drain on society. Compared with patients without bowel symptoms, they have, on average, more nongastrointestinal complaints and they tend to seek medical attention more for those problems. The condition accounts for an estimated 2.4 to 3.5 million physician visits per year in the United States, and for an estimated 2.2 million medical prescriptions (5). Hahn et al $(10,11)$ conducted two studies that evaluated health resource utilization. The first study (10) showed that, regardless of the severity of IBS symptoms (graded as mild, moderate, severe and very severe), there was very little difference in the use of health care resources among the patients. Those with mild and severe symptoms had the same amount of physician visits, inpatient hospital stays and emergency room visits. The second study (11) compared the consultation patterns of patients with IBS in both the United States and United Kingdom over a 12-month period. The results indicated that there was no significant difference in the use of health care resources between the two countries except that physician visits tended to be 


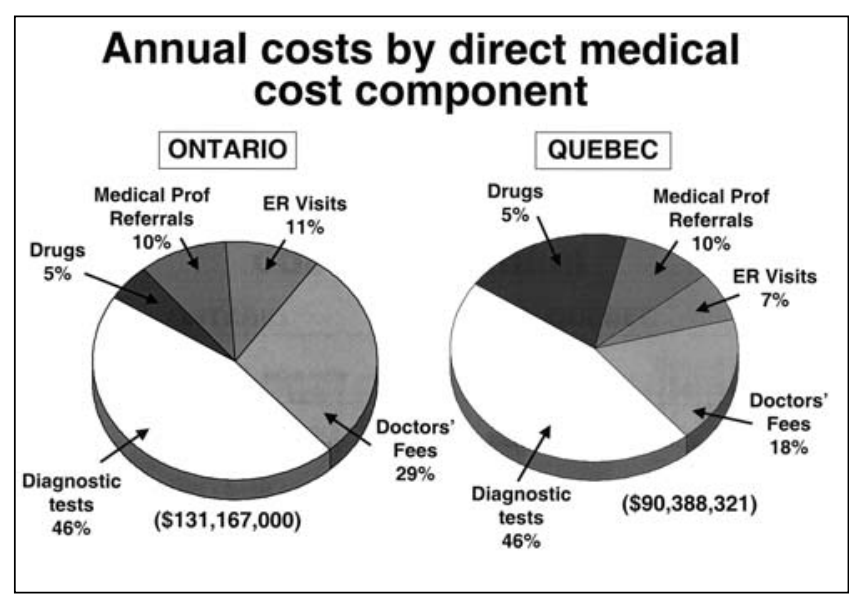

Figure 2) Annual costs ( $\$ \mathrm{CAN}$ ) by direct medical cost component for Ontario and Quebec. ER Emergency room. Data from reference 1

slightly greater for patients in the United Kingdom. Approximately $75 \%$ of patients in each group used a prescription medication.

A study by Talley et al (12) in 1995 found that, over a one-year period, $88 \%$ of subjects with IBS incurred direct medical charges compared with $86 \%$ for patients with some symptoms of IBS and $83 \%$ for controls. The annual costs of health care use for a patient with IBS were found to be almost double those of the control patient who had no gastroenterological symptoms. The overall median charges incurred by subjects with IBS were US $\$ 742$ compared with US $\$ 614$ for subjects with some symptoms and US $\$ 429$ for the controls. Thus, the mean differences in annual costs for these patients compared with either patients with other gastroenterological symptoms or patients with no gastroenterological symptoms were US $\$ 128$ and US $\$ 313$, respectively. Furthermore, the odds for incurring some charges were found to be 1.6 times greater in subjects with IBS relative to those without symptoms. In the United States householder study (13), patients with IBS were found to have 1.6 times more physician visits per year than patients with no gastroenterological symptoms and they visited the physician 3.8 times more often for nongastroenterological complaints than patients with no gastroenterological symptoms.

A study by Wells et al (14) estimated that, in 1995, the direct costs associated with this condition over a one-year period in the United Kingdom averaged $£ 45.6$ million. The total expenditures were based on the following costs: physician visits (£13.1 million), prescribed medications ( $£ 12.5$ million), hospital outpatient visits (£16.6 million) and inpatient admissions ( $£ 3.4$ million). In Canada, $42 \%$ of IBS patients used a primary care facility, referral centre or specialty consultations. These costs represent $24 \%$ of the total Canadian expenditure for IBS. Other direct costs of IBS in Canada, shown in Figure 2, can be divided into the following categories; $46 \%$ for diagnostic tests, $12 \%$ for nonprescription and prescription medications, $10 \%$ for medical-professional referrals and $9 \%$ for emergency room visits. For example, in Ontario and Quebec, these direct costs per year average $\$ 131$ million and $\$ 90$ million, respectively (1).
The economic impact of this disease is very much influenced by the associated indirect costs. Studies have indicated that IBS patients tend to miss three times as many days from work as patients not afflicted with the illness. Patients also report more often that they are too sick to work and they tend to take more time off to visit the physician (13). A study by Hahn et al (11) evaluated the impact of IBS on the work habits, over a four-week period, in patients from the United States and the United Kingdom. The results indicated that the two groups were comparable in the amount of workdays missed, and the amount of cut back in their workdays due to this illness. On average, the patients in each group lost two days of work and cut back on their workday three times a month. Other impacts on work included a high proportion (United States to United Kingdom) of each group that quit or lost their job (12\% to $17 \%$ ), changed job ( $9 \%$ to $18 \%$ ), changed schedule ( $8 \%$ to $9 \%$ ), worked fewer hours (15\% to $19 \%$ ), refused a promotion ( $16 \%$ to $26 \%)$ or changed to working at home ( $12 \%$ to $11 \%)$, all to accommodate their illness. On a yearly basis, patients with IBS miss up to five more days of work or school than people who do not have IBS. A study by Drossman et al (13) estimated that the economic loss due to work or school absences is equivalent to $\$ 1$ million Canadian yearly.

The intangible costs such as the pain, suffering and reduction in the quality of life endured by patients are by far the hardest to quantify. The lower abdominal pain and discomfort caused by the disease, together with the altered bowel habits, reduce the well-being and, therefore, affect the overall quality of life for patients with IBS. Physicians and health care providers are becoming more and more conscious that patient well-being is a vital part of health, which encompasses physical functioning, mental health, social interaction and overall quality of life. Although IBS is not life-threatening, patients report limited and constrained lives that have been modified to cope with their disease. In a study conducted by Wells et al (14), the qualities of lives of patients with different medical afflictions were compared and examined. Mean scores on the Short Form-36 IBS-specific quality of life (IBSQOL) questionnaire for patients with diabetes, acute myocardial infarction, hypertension and clinical depression were compared with the IBS mean for a tertiary care group and with the national norms for nonpatients. With the exception of the physical functioning index, patients with IBS were comparable with people with clinical depression in exhibiting the worst quality of life. Both groups showed significantly lower levels of emotional health, social functioning and mental health than the other groups.

The negative impact of the disease on the patient's quality of life is especially evident when the results of the IBSQOL (a disease-specific quality of life instrument) questionnaire are examined. The lowest scores obtained are for emotional, social and physical functions when compared with the theoretical normative values (11). IBS is a multifaceted disease in terms of its somatic and psychosocial fac- 
tors. The fluctuating history and relationship of this disease to other functional gastrointestinal disorders predisposes some patients to receive unnecessary health care, including hospitalization and surgery. Taking all these factors into consideration, physicians who care for patients with IBS can help to reduce the expenses related to this syndrome. From the standpoint of health care utilization, IBS is not just a gastrointestinal problem, it is a much more global problem.

\section{GENERAL TREATMENT APPROACH}

In 1997, the American Gastroenterological Association developed guidelines to assist physicians in the diagnosis and management of patients with IBS (15). The general treatment approach for all patients includes establishing an effective therapeutic relationship, providing patient education and reassurance, helping with dietary and lifestyle modifications, initiating treatment and reassessing treatment after a three- to six-week period. The value of an effective physician-patient relationship is supported by the fact that patients with IBS have a $30 \%$ to $88 \%$ placebo response rate, regardless of treatment (5). Further studies have suggested that a positive physician-patient interaction leads to greater patient compliance and satisfaction, and that attention by the physician to the emotional needs of the patient affects outcome.

A study by Owens et al (16) explored the benefits of a positive physician-patient interaction and showed that the number of patient visits to a physician was inversely proportionate to the strength of the physician-patient interaction. A reduced use of ambulatory health care services by patients was observed when a positive interaction between the physician and the patient existed. Physicians who determine the patient's understanding of the disease, fully explain all facets of the illness and address all the patient's concerns greatly decrease the number of subsequent visits required by the patient. Patient education and reassurance are an essential part of treatment. Education involves explaining to the patient that the symptoms are not fabricated and that they have a definite physical nature.

\section{REFERENCES}

1. Bentkover JD, Field C, Greene EM, Plourde V, Casciano JP. The economic burden of irritable bowel syndrome in Canada. Can J Gastroenterol 1999;13(Suppl A):89A-96A.

2. Jones R, Lydeard S. Irritable bowel syndrome in the general population. BM] 1992;304:87-90.

3. Thompson GW, Gick M. Irritable bowel syndrome. Semin Gastrointest Dis 1996; 7:217-29.

4. Mitchell CM, Drossman DA. Survey of the AGA membership relating to patients with functional gastrointestinal disorders. Gastroenterology 1987;92:1282-4.

5. Drossman DA, Whitehead WE, Calmilleri M. Irritable bowel syndrome: a technical review for practice guideline development. Gastroenterology 1997;112:2120-37.

6. Thompson GW. Irritable bowel syndrome: prevalence, prognosis and consequences. Can Med Assoc J 1986;134:111-3.

7. Kay l, Jorgensen T, Jensen KH. The epidemiology of irritable bowel syndrome in a random population: prevalence, incidence, natural history and risk factors. J Int Med 1994;236:23-30.

8. Maxwell PR, Mendall MA, Kumar D. Irritable bowel syndrome. Lancet 1997;350:1691-5.

9. Talley NJ. Scope of the problem of functional digestive disorders.
Dietary management and lifestyle modifications are often an important part of the therapeutic regimen. In some patients, certain dietary substances can be associated with increased symptoms. However, most patients are thought to experience a generalized effect of food ingestion on intestinal reactivity. Restrictive diets in most cases are usually unnecessary and should be avoided (5). Modifying lifestyle to reduce stressors, both physical and psychological, can improve symptoms. Research indicates that psychosocial factors play a crucial role in the symptoms. Psychological stress is known to augment the symptoms, and patients who develop IBS tend to suffer from higher anxiety than those who do not $(8,11)$.

The final step in the therapeutic approach is to initiate treatment and follow-up with the patient in three to six weeks. To date, no medication has been convincingly shown to be of benefit in the treatment of the whole IBS complex, so pharmacotherapy has rarely played a central role (5). At present, the guiding principle consists of individualizing the treatment according to the nature and severity of the symptoms, the degree of physiological disturbances, the functional impairment and the presence of psychological difficulties affecting the course of the illness.

Our understanding of the physiopathology of this biopsychosocial disease has improved remarkably over the past few years. This new understanding allows the medical community to offer a clearer explanation of this disease to patients and to strengthen the physician-patient relationship. The patient feels that he or she is participating in the understanding and management of these problems. It has been shown that a strong physician-patient relationship is a determining factor in symptom improvement (16). Given this correlation, it seems clear that an adequate physicianpatient relationship is one of the key factors in influencing the cost of health care service demands for IBS. Long term adjustment of expenditures should focus on decreasing health care utilization through a better physician-patient relationship. This, in turn, would no doubt have an impact on increasing patient well-being and decreasing costs associated with work and production losses.

Eur J Surg Suppl 1998;582:35-41.

10. Hahn BA, Kirchdoerfer LJ, Fullerton S, Mayer E. Patient-perceived severity of irritable bowel syndrome in relation to symptoms, health resource utilization and quality of life. Aliment Pharmacol Ther 1997;11:553-9.

11. Hahn BA, Yan S, Strassels S. Impact of irritable bowel syndrome on quality of life and resource use in the United States and United Kingdom. Digestion 1999;60:77-81.

12. Talley NJ, Gabriel SE, Harmsen SW, Zinmeister AR, Evans RW. Medical costs in community subjects with irritable bowel syndrome. Gastroenterology 1995;109:1736-41.

13. Drossman DA, Li Z, Andruzzi E, et al. U.S. householder survey of functional gastrointestinal disorders. Prevalence, sociodemography, and health impact. Dig Dis Sci 1993;38:1569-80.

14. Wells NEJ, Hahn BA, Whorwell PJ. Clinical economics review: irritable bowel syndrome. Aliment Pharmacol Ther 1999;11:1019-30.

15. Drossman DA, Whitehead WE, Calmilleri M. American Gastroenterological Association medical position statement: irritable bowel syndrome. Gastroenterology 1997;112:2118-9.

16. Owens DM, Nelson DK, Talley NJ. The irritable bowel syndrome: long term prognosis and physician-patient interaction. Ann Intern Med 1995;122:107-12. 


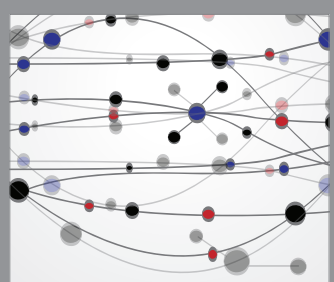

The Scientific World Journal
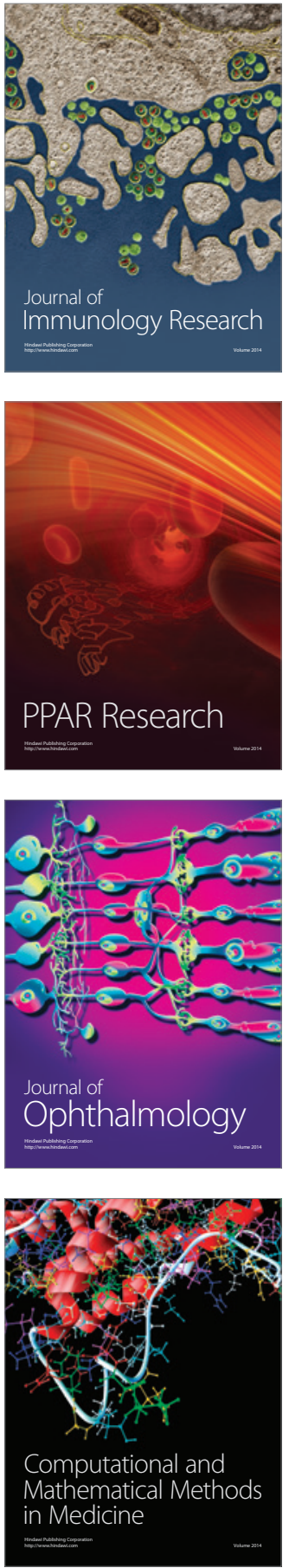

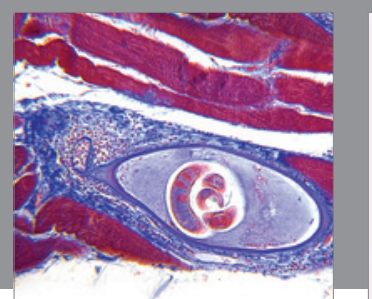

Gastroenterology Research and Practice

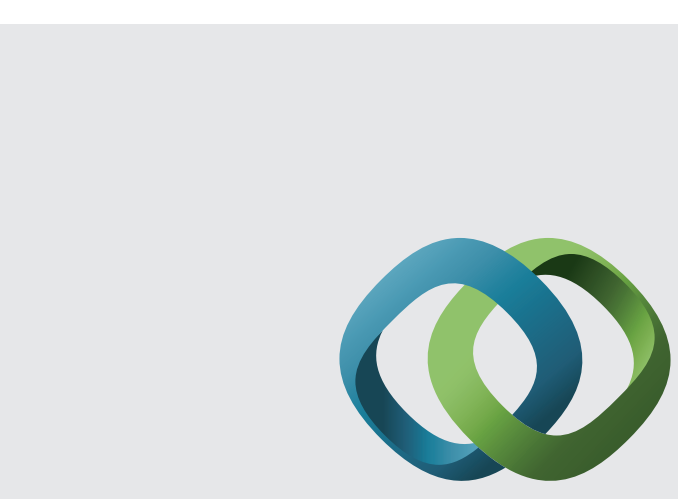

\section{Hindawi}

Submit your manuscripts at

http://www.hindawi.com
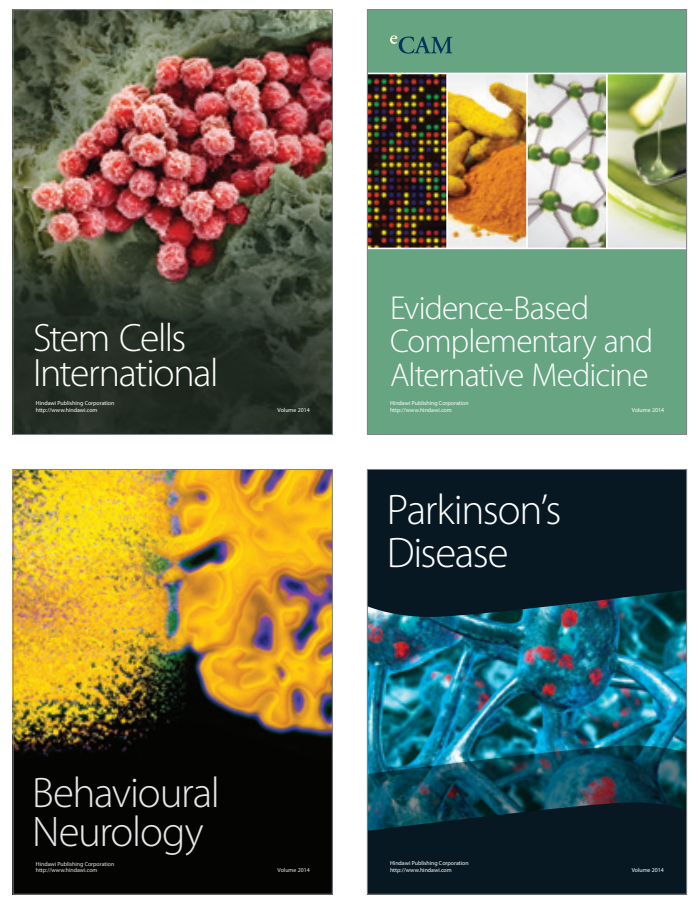
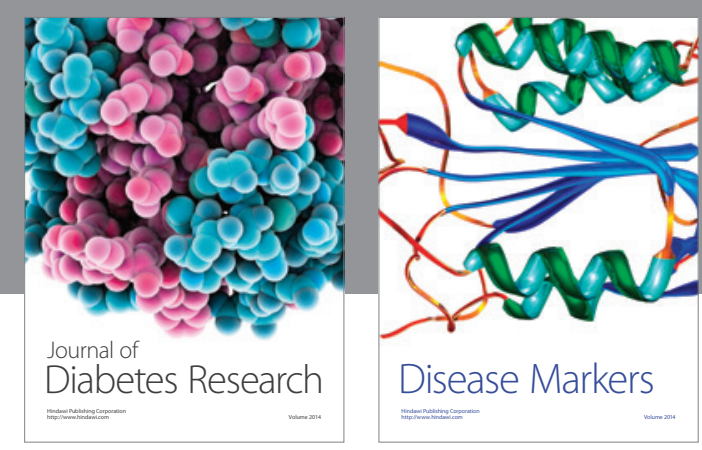

Disease Markers
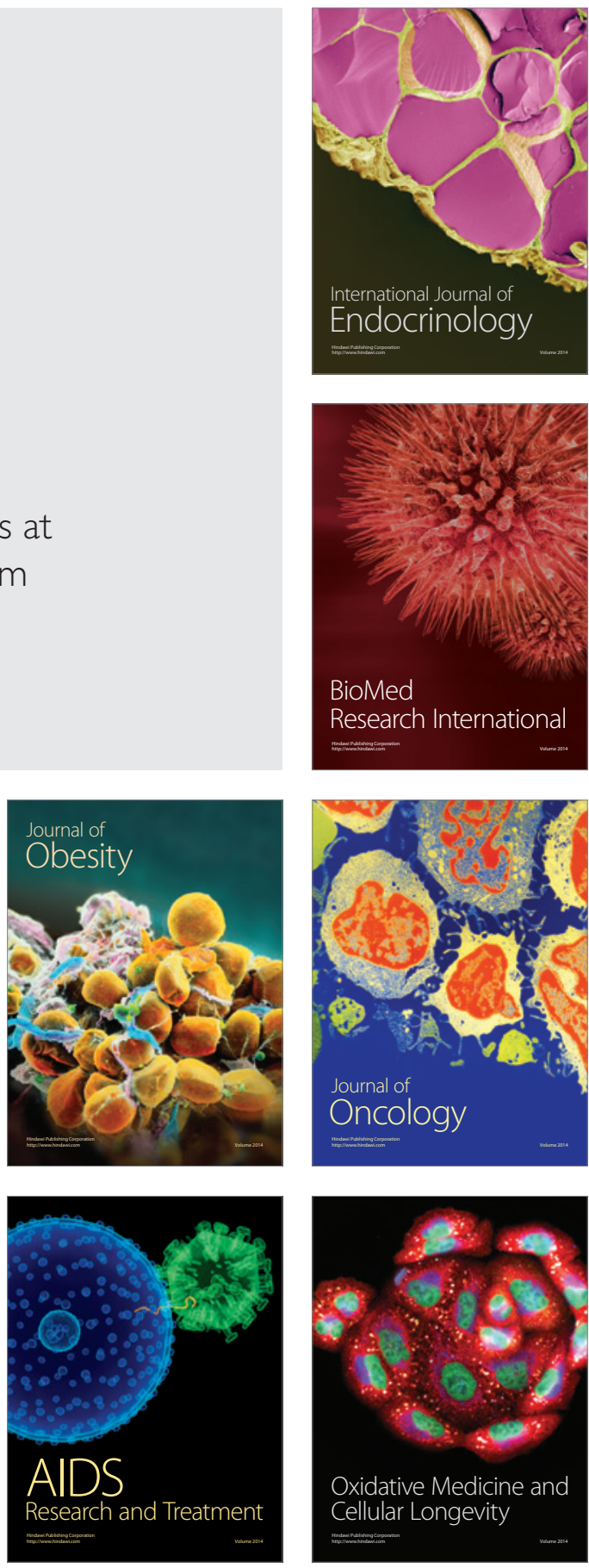